(Bull. d'Hist., 1928) and by Hibbard for Discoglossus (Jour. Morph. Physiol., 1928).

In their chemistry the vacuoles of the eggs of Rana, Ophiocephalus, and Rita are diametrically different from the Golgi elements. Whereas the latter consistently go jet-black in either Da Fano or MannKopsch or Kolatschev, and cannot be stained with neutral red, the former do not show the slightest amount of blackening however heavy the impregnations, and are stainable with that vital dye. The Golgi elements are certainly lipoidal (fat-like), whereas the vacuoles represent an aqueous material of a nonlipoidal and non-fatty nature.

I desire to pay tribute to the brilliant researches of Prof. Parat and his collaborators who have focused attention on a hitherto neglected cytoplasmic component, the vacuome, which in oogenesis may give rise to albuminous yolk as in Perca, Pygosteus, and Ophiocephalus. But the vacuome is not the Golgi apparatus as claimed by the Parat school. The classical Golgi apparatus may often be vesicular or vacuolar in form as in so many eggs (Nath, Gresson, etc., etc.) and even in other cells, for example, Protozoa (Hirschler, Z. Zellf., 1927), but chemically and functionally it is a fundamentally different material from the vacuome. The Golgi vesicle is not a mere vacuole, but is surrounded by a thick lipoidal cortex which is characteristically argentophile and osmiophile.

Department of Zoology, VISHWA NATH.

Government College, Lahore, India, Aug. 2.

\section{Manner in which Flaps of various Materials fracture along their Bases.}

WHILE studying the various methods in which osteoplastic flaps for exposing the brain and its membranous coverings may be formed from the human skull, my attention has been directed to the way in which fracture takes place along the bases of bone
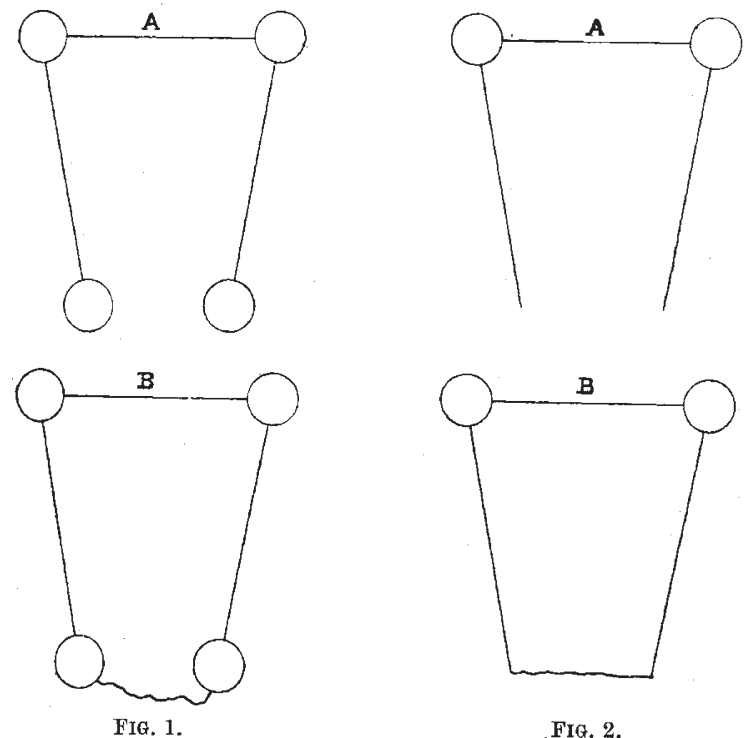

flaps. The type of fracture appears to depend upon the manner in which the limits of the proposed base line are cut.

If, by cutting three sides, a flap is fashioned so that the base lies between two trephine holes (Fig. 1, A), and the flap so formed is then bent outwards until fracture occurs along the base line, this line will be found to be jagged and irregular (Fig. 1, B). If, however, by cutting three sides, the flap is fashioned so that the base lies between saw cuts (Fig. 2, A), and the flap so formed is bent outwards until fracture occurs along the base line, this line will be found to be even and regular (Fig. 2, B). I have verified this on numerous occasions, and have also fashioned flaps from, and performed the same experiments with, other materials, such as three-ply wood, dried bone, and cardboard, and find that the results are constant in each case. The difference in the type of fracture of the base line no doubt depends upon the difference in concentration of stress at its limits.

In an article on osteoplastic craniotomy in the current number of the British Journal of Surgery, I have directed attention to the facts outlined here, but I believe that they may have a wider application than cranial surgery, and hence this letter.

LAMBERT ROgERs.

Welsh National School of Medicine,

The Royal Infirmary, Cardiff,

Oct. 20.

\section{Autosyndesis among Crepis setosa Chromosomes.}

IN a paper ${ }^{1}$ dealing with the connexion between cytology and taxonomy, Prof. Tischler makes a state. ment to the effect that the four haploid chromosomes of Crepis setosa conjugate to form two pairs at the time of meiosis in the species hybrid Crepis biennis $(n=20) \times C$. setosa $(n=4)$. This he credits to us in a paper ${ }^{2}$ in which we described a constant fertile form, $C$. artificialis, derived from these two species. Prof. Tischler also expresses doubt as to the occurrence of such a phenomenon. He says (p. 48): "Nicht dur die 20 Chromosomen der ersten Art schlossen sich autosyndetisch zu Paaren zusammen, sondern auch die 4 der zweiten. Wir erhalten so 12 Gemini. Und es ist doch die Zerlegung der vier Chromosomen in zwei einander ' homologe' Paare mehr als unwahrscheinlich."

The purpose of this letter is to direct attention to the fact that Prof. Tischler has misread our description of the origin of Crepis artificialis. This new species arose from a fourth generation plant of the cross between the two species $C$. setosa $(n=4)$ and $C$. biennis $(n=20)$. In the $F_{1}$ the 20 biennis chromosomes conjugate to form ten pairs while the setosa chromosomes remain as univalents and are distributed at random to the gametes. Thus all the $F_{2}$ progeny receive 20 biennis chromosomes ( 10 pairs) and a random number from setosa. $C$. artificialis arose from the union of two gametes, each of which had received 10 biennis chromosomes and the same two setosa chromosomes, thus producing a diploid complex having 20 biennis chromosomes (10 pairs) and 4 setosa chromosomes (2 pairs). Only two of the four types of setosa chromosomes are present in the fertile form called Crepis artificialis. This fact was re. peatedly pointed out in the paper to which Prof. Tischler refers.

The following quotations from our original paper should be sufficient to correct the statement quoted above. "The two setosa chromosomes in the artificialis complex are quite readily recognized by their morphological characters and each is present twice. These are the first and fourth types mentioned above" (p. 309). "Crepis biennis, a species with 20 pairs of chromosomes, has been crossed successfully with two other species of Crepis, namely, C. parviflora Desf. and $C$. rubra L. During gamete formation in these $F_{1}$ hybrids, Mrs. Lesley found that, as in the biennis. setosa $F_{1}$, the 20 biennis chromosomes conjugate to form 10 pairs, while the chromosomes from the other

No. 3185, VoL. 126] 